\title{
E o cachimbo que não foi eterno: o negro no livro dos afiguraves
}

And the pipe that was not eternal: The Negro in the book of afiguraves

\section{Elen Karla Sousa da Silva}

Universidade Federal do Rio Grande do Sul - UFRGS - Porto Alegre - Rio Grande do Sul - Brasil

Ciro Leandro Costa da Fonseca

Universidade Estadual do Rio Grande do Norte - UERN - Mossoró - Rio Grande do Norte - Brasil

\section{Introdução}

Defensor e pesquisador da história e da cultura em suas mais profundas raízes, o jornalista Franklin Jorge elaborou, com sua obra "O Livro dos Afigurave", a face da identidade cultural de todas as classes pertencentes à sociedade potiguar, mais especificamente, à luisgomense. Por meio de uma longa pesquisa de campo, entrevistou todos os representantes dessa sociedade, dando vez e voz a membros do grupo social cujas biografias foram historicamente silenciadas.

A obra, tecida a muitas mãos, é fruto de um trabalho coletivo, como toda memória que é narrada e transmitida no seio das relações de uma comunidade. Sua contribuição literária, memorialista e social é a do reconhecimento dos indivíduos no curso da história local, regional e nacional, sua inscrição. A escritura ilumina e dá voz aos indivíduos excluídos da elite local, branca e hegemônica; escreve sobre as trajetórias de vidas não enxergadas como componentes importantes e significativos, trazendo à cena personagens intencionalmente esquecidos pela sociedade, proporcionando-Ihes o reconhecimento de suas identidades, por eles e pelo grupo social.

Nesta interação, o autor e seus colaboradores combatem o preconceito, o racismo e a violenta eliminação simbólica dos povos excluídos, negros ou brancos, retirando-Ihes da inexistência social a que foram forçados ao longo do tempo e do apartheid social. Na obra, a Vila de Bom Jesus, o autor preferiu chamar a atual cidade de Luís Gomes por seu antigo nome, que remonta aos tempos do Brasil colonial, é comparada a uma miniatura de Macondo, cidade e espaço social onde se passa a narrativa da obra "Cem Anos de Solidão", de Gabriel García Márquez. Assim como a fictícia aldeia de vinte casas de barro e taquara, como as casas de taipa cobertas de palha de coqueiro da Rua do Cachimbo Eterno, lugar onde se vivia na mais absoluta pobreza. Bom Jesus, tecida no veio narrativo de Franklin Jorge, apresenta-se como uma vila cheia de castas sociais, mas onde todos os moradores se tornam autores de seus contos, de suas histórias de vida transformadas em crônicas históricas, num todo que se transforma num romance histórico, num folhetim da Serra, como surgiram os primeiros romances.

Ancorado em ampla pesquisa oral, o livro oportuniza um olhar sobra a história e a cultura dos povos negros da cidade de Luís Gomes e da região, ao trazer à cena os moradores das ruas antes habitadas predominantemente por descendentes afro-brasileiros, numa descrição apurada dos costumes que marcaram o início do século $X X$, garimpando vozes em entrevistas transformadas em crônicas, que embora sob o viés literário, não perderam o rigor do resgate histórico de pessoas e contextos sóciohistóricos. Assim é o resgate da Rua do Cachimbo Eterno, batizada com esse nome por ser a rua dos negros fumadores de cachimbo, excluídos historicamente desde o final do século XIX, uma rua 
constituída de casebres de taipa e teto de palha, com moradores que juntamente com os moradores da Rua do Emboque e da Rua das Almas, não tinham acesso ao centro da Vila nem da cidade, depois da emancipação política. Eram os moradores mais pobres e discriminados da cidade, numa área historicamente segregada. Seus moradores eram constituídos pelos negros fumadores de cachimbo, daí a sua denominação histórica de que o Cachimbo seria eterno, ou seja, estes povos excluídos não ascenderiam socialmente, os negros continuariam ocupando os lugares da separação de classes, não teriam acesso ao centro da vila e às ruas consideradas nobres.

Como todo discurso, é permeado pela luta de classes, pelos conflitos sociais e a identidade cultural é elaborada nessa dialética, a cultura negra da Rua do Cachimbo Eterno, negada e apartada pela elite branca, produzia enunciados em resposta, por meio do maracatu profano que satirizava os costumes e os acontecimentos dos ricos soberbos, numa crônica social sobre a vila, por meio do improviso e da oralidade, tão características da cultura popular nordestina. As habitações da Rua do Cachimbo Eterno, como a grande parte das residências dos povos remanescentes dos negros escravizados, não possuíam móveis e os moradores comiam sobre esteiras ou sentavam no chão. Esta vida ao rés do chão traz uma cultura popular dos povos negros que não se separa da experiência da escravidão, da segregação racial e social perpetuada do final do século XIX até meados do século XX.

Conforme teorizou Paul Gilroy, em sua obra "O Atlântico Negro", podemos voltar o olhar para - maracatu dos negros do Cachimbo como remanescente dessa experiência, um maracatu profano e satírico que glosava a vida das elites, que em represália pelas chacotas sofridas discriminavam os moradores do Cachimbo, chamando-os de "cus-delinha", por se vestirem humildemente, com roupas remendadas. A Rua do Cachimbo, enquanto núcleo das pessoas pobres e negras da histórica vila, possuía uma cultura irreverente e de resistência. Esses moradores começaram a ser integrados ao restante da sociedade local nos anos 50, pelo padre da cidade, Raimundo Caramuru, que lutou para quebrar os grilhões da segregação e passou a realizar folguedos nas ruas afastadas e discriminadas do Emboque, Cachimbo Eterno e das Almas, e as pessoas do centro passaram a interagir com a cultura negra.

Além da memória do maracatu e dos moradores das ruas dos negros, o livro traz uma entrevista com a senhora Joana D'Arc Lopes, representante dos negros da cidade, que marca a sua crônica sob o signo da resistência: "Sou uma negra que não gosta de adular ninguém". Esse discurso traz as marcas de uma época em que foi discriminada e mostra a sua resistência em falar da sua história de vida, poucas vezes iluminada e oportunizada pelo interesse da história e da literatura. Joanita, como ficou conhecida por seu grupo social, teve como ponto significativo de sua biografia o preconceito social e racial, marcas que estão subjacentes em sua entrevista. Porém, de personalidade forte, como os negros do Cachimbo Eterno, nunca se deixou abater nem silenciou a sua identidade. Relembra, enquanto representante dos povos negros da cidade diante de uma sociedade fechada para eles, os chamados moradores da Rua da Frente, no Quadro da Matriz, vingados noite adentro pelos versos satíricos do maracatu negro e profano das Ruas das Almas e do Cachimbo. A Rua das Almas a caminho do cemitério da vila, afastada do centro. Joanita relembra sua mocidade já advertindo: "Não gosto de fuxico nem de conversar besteira”, apresenta-se num rompante. "Não faço floreiros nem gosto de rapapés. Acredite que aqui tem gente mais ruim do que eu. Porém, nessas circunstâncias, eu entrego a Deus". Nessa fala, narrada pelo autor, podemos perceber a posição de defesa como marca de uma discriminação histórica sofrida pelos negros. Ao se afirmar como uma negra que não gosta de adular ninguém, Joanita deixa transparecer as relações de servidão dos negros para com os brancos, com as quais ela buscou romper, e as discriminações que sofreu entrega a Deus, como forma de luta e resistência contra esta hegemonia branca sofrida pelo seu grupo, representado em sua 
voz memória, pois poucas vezes os negros tiveram a voz representada na literatura da região, o que dá pioneirismo à obra. Como se os negros pudessem, através da narrativa, sair das ruas do Cachimbo Eterno, do Emboque e das Almas e invadir as ruas da Frente, dos bem-nascidos e abastados. Em sua juventude, ela destaca que só gostava de viver dançando, bebendo, brincando, ao invés de estar servindo aos brancos, o que lhe dá um caráter de luta contra o que foi negado ao seu povo, enquanto apenas trabalhava e servia como escravos.

Outro ponto significativo com relação à cultura negra. narrado na entrevista transformada em crônica, do senhor Quinco Barbosa, e que enfatiza a submissão histórica dessa gente, é o fato do negro José Martins, que lutou na Guerra do Paraguai e viveu em Bom Jesus, ser fã do Conde D’Eu de Orléans, marido da Princesa Isabel, um militar que nessa guerra sanguinária recrutou como "voluntários da Pátria" negros e pobres, para morrerem e realizar uma limpeza étnica no Brasil. "Ele me contava que na guerra as atrocidades se tornavam corriqueiras. Muita gente daqui foi levada, contra a própria vontade, para lutar no Paraguai. Por isso, muitos meninos de apenas dez anos se casavam, para fugirem à convocação do Imperador". Apesar desses acontecimentos, o negro se tornou fã do conde, em razão das histórias da guerra contadas por José Martins, o senhor Quinco também se tornou fã do conde, pois batizou o primeiro filho do seu segundo casamento de Conde D'Eu de Orléans. Seu Quinco viveu mais de cem anos e é representante de um grupo que conheceu as divisões entre negros e brancos ao longo do século $X X$, pois Quinco pertencia ao outro grupo, a elite da vila, sendo proprietário de terras, exercendo os cargos de primeiro prefeito constitucional do município e de adjunto de promotor.

Hoje, a Rua do Cachimbo Eterno, bem como as ruas das Almas e do Emboque estão urbanizadas, mais próximas das Ruas da Frente, geográfica e culturalmente; hoje, tornou-se uma avenida ornada de canteiros e jardins. De forma simbólica, essa transformação nas áreas historicamente discriminadas e mais pobres da cidade se constitui como uma repaginação não só física, mas uma nova visão sobre a cultura dos negros. Antes se podia ouvir o canto do maracatu, à noite, com seus versos profanos e carnavalescos como: "Maracatu, maracatu, maracatu,/ Quando for a meia-noite./ Tire a roupa e dance nu." De forma alegórica, esses versos tiravam a roupa da hipocrisia da elite da época e ocupavam o seu ligar social à noite, como nas antigas senzalas. Hoje, os versos dos negros do Cachimbo Eterno entoam na memória dos antigos moradores negros ou brancos, na memória coletiva da cidade, como parte da sua identidade cultural, que não pode continuar negando a contribuição do negro e da sua cultura. Esses não eram alheios nem alienados quanto a sua própria condição e respondiam com suas manifestações à discriminação da sociedade branca e abastada, como relembra a obra "O Livro dos Afiguraves". Daí a sua importância, por trazer à tona um capítulo da história dos negros no município de Luís Gomes e no Estado do Rio Grande do Norte, que não era conhecido pelas novas gerações.

Essa cultura, guardada como um segredo na alma dos povos negros, principalmente os versos satíricos do maracatu, pode ser transmitida não só aos descendentes dos primeiros moradores da Rua do Cachimbo Eterno, mas a todos os leitores, quebrando o silêncio e descortinando uma experiência histórica que abre um laboratório para o estudo da presença e da cultura dos povos negros da região. A obra de Franklin Jorge ilumina, dessa forma, a trajetória de toda uma comunidade, contribuindo para o processo de reconhecimento histórico e identitário. Assim, o Cachimbo da discriminação não foi “Eterno".

\section{Referências}

FRANKLIN, Jorge. O livro dos afiguraves: folhetim de Bom Jesus da Serra de Luís Gomes. Natal: Feedback, 2015. 
SILVA, Elen Karla Sousa da. E O CACHIMBO QUE NÃO FOI ETERNO: O NEGRO NO LIVRO DOS AFIGURAVES. Signo, Santa Cruz do Sul, v. 45, n. 84, nov. 2020. ISSN 1982-2014. Disponível em: <https://online.unisc.br/seer/index.php/signo/article/view/6974>. doi:https://doi.org/10.17058/signo.v45i84.6974. 